\title{
Methylprednisolone Pulses in West Syndrome: A New Weapon in the Armory-Is it Needed?
}

\author{
Rishi Sharma $^{1} \cdot$ Sheffali Gulati $^{1}$ \\ Received: 12 April 2021 / Accepted: 20 April 2021 / Published online: 20 May 2021 \\ (C) Dr. K C Chaudhuri Foundation 2021
}

Adrenocorticotropic hormone (ACTH) has been the standard of care in structural West Syndrome over the last three decades and has stood the test of time. It has multiple mechanisms of action, one being immunomodulation by which it reduces brain inflammation and neuronal excitability [1]. However, the need to develop alternate regimes has always been sought in view of the practical difficulty of daily injections, accessibility, cost of therapy and need to store at low temperature, particularly in context of low-income countries. Therefore, preferred initial therapy differs in different geographic locations. In a resource-limited setting, the ability of high-dose oral prednisolone (doses $>4 \mathrm{mg} / \mathrm{kg}$ ) to induce electroclinical resolution offers a cost-effective treatment strategy [2]. There is growing evidence that high-dose prednisolone has equivalent efficacy compared to ACTH in terms of short- and long-term seizure control with overall poor outcome [3].

The need to intensify the treatment strategy with addition of methylprednisolone prior to high-dose prednisolone has been a subject for investigation. In this issue of the Journal, Rajpurohit et al. reported their open-label, pilot study comparing safety, feasibility, and short-term effectiveness of methylprednisolone followed by oral prednisolone with ACTH [4]. This study is one of the first studies to compare the two treatment strategies. The primary outcome measure was rightly chosen as complete electroclinical cessation of spasms. The response in both groups was quite low as compared to those observed elsewhere, which was attributed to treatment lag. Another factor which could affect short-term outcome is mean severity score on pretreatment EEG. Kramer et al., while validating their scale, had detected significant correlation between higher hypsarrhythmia score and poorer outcome;

Sheffali Gulati

sheffaligulati@gmail.com

1 Child Neurology Division, Department of Pediatrics, All India Institute of Medical Sciences, New Delhi 110029, India however, clinical significance of such an observation is unknown [5].

Previous prospective observational studies by Mytinger et al. (2010) and Yeh et al. (2017) with a relatively small sample size had suggested rapid response, but response rates were not superior when compared to other studies with highdose prednisolone $[6,7]$. Another group with high dose oral prednisolone should have been considered in the study considering ease of administration, need for hospitalization, and cost effectiveness.

Variable underlying etiology and severity also need to be considered in response assessment. Subgroup analysis in these different groups will not only identify predictors of poor response but also need for intensified treatment.

In terms of safety and tolerability methylprednisolone followed by oral prednisolone is likely to have an upper hand compared with daily ACTH injection and this was shown in the given study as well. However, in view of near-equal efficacy of high-dose oral prednisolone alone, a comparative study of the three treatment strategies is required [3].

\section{Declarations}

Conflict of Interest None.

\section{References}

1. Brunson KL, Avishai-Eliner S, Baram TZ. ACTH treatment of infantile spasms: mechanisms of its effects in modulation of neuronal excitability. Int Rev Neurobiol. 2002;49:185-97.

2. Lux AL, Edwards SW, Hancock E, et al. The United Kingdom infantile spasms study (UKISS) comparing hormone treatment with vigabatrin on developmental and epilepsy outcomes to age 14 months: a multicentre randomised trial. Lancet Neurol. 2005;4: $712-7$.

3. Wanigasinghe J, Arambepola C, Ranganathan SS, Sumanasena S. Randomized, single-blind, parallel clinical trial on efficacy of oral prednisolone versus intramuscular corticotropin: a 12-month assessment of spasm control in west syndrome. Pediatr Neurol. 2017;76: 14-9. 
4. Rajpurohit M, Gupta A, Madaan P, Sahu JK, Singhi P. Safety, feasibility and effectiveness of pulse methylprednisolone therapy in comparison with intramuscular adrenocorticotropic hormone in children with west syndrome. Indian J Pediatr. 2020. https://doi.org/10. 1007/s12098-020-03521-7.

5. Kramer U, Sue WC, Mikati MA. Hypsarrhythmia: frequency of variant patterns and correlation with etiology and outcome. Neurology. 1997;48:197-203.
6. Mytinger JR, Quigg M, Taft WC, Buck ML, Rust RS. Outcomes in treatment of infantile spasms with pulse methylprednisolone. J Child Neurol. 2010;25:948-53.

7. Yeh HR, Kim MJ, Ko TS, Yum MS, You SJ. Short-term outcome of intravenous methylprednisolone pulse therapy in patients with infantile spasms. Pediatr Neurol. 2017;71:50-5.

Publisher's Note Springer Nature remains neutral with regard to jurisdictional claims in published maps and institutional affiliations. 